\title{
Isolated Rat Dental Pulp Cell Culture and Transplantation with an Alginate Scaffold
}

\author{
By \\ Shiro FUJIWARA, Shunji KUMABE and Yasutomo IWAI \\ Department of Oral Anatomy, Osaka Dental University, 8-1, Kuzuhahanazono-cho, Hirakata-shi, \\ Osaka 573-1121, Japan \\ - Received for Publication, February 17, $2006-$
}

Key Words: Dental-pulp-derived cell, Rat, Cell culture, Alginate scaffold, Transplantation

\begin{abstract}
Summary: Many studies have been conducted on tissue stem cells in the field of regenerative medicine, and cultured dental pulp mesenchymal cells have been reported to secrete dentin matrix. In the present study we used alginate as a scaffold to transplant subcultured rat dental-pulp-derived cells subcutaneously into the back of nude mice. We found that when $\beta$-glycerophosphate was added to the culture medium, the mRNA of the dentin sialophosphoprotein (DSPP) gene coding dentin sialoprotein (DSP) and dentin phosphoprotein (DPP) was expressed, and an increase in alkaline phosphatase, an early marker of odontoblast differentiation, was also demonstrated. Six weeks after implantation, subcutaneous formation of radiopaque calcified bodies was observed in situ. Immunohistochemical and fine structure studies identified expression of type I collagen, type III collagen, and DSP in the mineralizing transplants, and isolated odontoblast-like cells began to form dentin-like hard tissue formation. Scattered autolyzing apoptotic cells were also observed in the transplants. The study showed that subcultured rat dental-pulp-derived cells actively differentiate into odontoblast-like cells and induce calcification in an alginate scaffold.
\end{abstract}

Several studies on the use of tissue stem cells in regenerative medicine have shown that cultured mesenchymal cells differentiate into bone, cartilage, muscle, tendon, adipose tissue, and bone marrow stroma ${ }^{1-5}$. Dental-pulp-derived cells display osteogenic and odontogenic differentiation potential in vitro, and interactions between the cultured cells, various growth and proliferation factors, and scaffolds have been studied in detail, because they affect the properties and form of regenerative biomaterials $^{6-9)}$. A human dental-pulp-derived cell culture has been developed, and hard tissue formation has been observed when the cells were transplanted with a hydroxyapatite/tricalcium phosphate (HA/TCP) scaffold into nude mice ${ }^{10}$.

Alginate is a biocompatible material used as a scaffold for culturing cartilage ${ }^{11-13)}$. In the present study we attempted to use the adaptability of the alginate scaffold for odontoblast differentiation of rat dental-pulp-derived cells transplanted subcutaneously into the lumbo-dorsal area of nude mice. Transplantation of alginate alone was performed in the control group.

\section{Materials and Methods}

Isolation and culture of dental-pulp-derived cells

Rat dental pulp was aseptically dissected from a 5-week-old male Wistar rat (Japan SLC Inc., Hamamatsu, Japan). The protocol (No. 05-02016: Culture of rat dental pulp stem cells) was approved by the Animal Research Committee of Osaka Dental University. The cells were isolated by exposure to collagenase type I $(4 \mathrm{mg} / \mathrm{ml}$; Wako Pure Chemical Industries, Osaka, Japan) and dispase (4 mg/ml; Gibco Lab., Grand Island, NY, USA) at $37^{\circ} \mathrm{C}$ for 40 minutes. The solution containing the isolated cells was filtered through a cell strainer (70 $\mu \mathrm{m}$; BD Falcon, Bedford, MA, USA), and after centrifuging the cells (1500 rpm, 3 min), Dulbecco's Modified Eagle Medium (DMEM, Nacalai Tesque, Inc., Kyoto, Japan) containing penicillin (100 units/ $\mathrm{ml}$; Gibco Laboratories), streptomycin $(100 \mu \mathrm{g} / \mathrm{ml}$; Gibco Laboratories), and fetal bovine serum (20\%; FBS, HyClone, Logan, UT, USA) was added. The primary culture was seeded on dishes $(35 \mathrm{~mm}$; BD Falcon) and cultured at $37^{\circ} \mathrm{C}$ under a $5 \% \mathrm{CO}_{2}$ at-

Correspondence: Dr. Shunji Kumabe, Department of Oral Anatomy, Osaka Dental University, 8-1, Kuzuhahanazono-cho, Hirakatashi, Osaka 573-1121, Japan. E-mail: kumabe@cc.osaka-dent.ac.jp 
mosphere. After reaching confluence, the cells were seeded at a $5000 / \mathrm{cm}^{2}$ cell concentration by gradient reduction with $10 \%$ FBS. The 3 rd passage cells were obtained after 1 month of cell subculture.

\section{Examination of cell differentiation}

Glycerol 2-phosphate disodium salt hydrate $(\beta$ GP; SIGMA-ALDRICH CHEMIE GmbH, Steinheim, Germany), which is said to accelerate cell differentiation, was added (experimental $\beta$-GP $(+)$ group) or not added (control $\beta$-GP (-) group) to the primary culture and subcultures. Each culture was seeded at $10,000 \mathrm{cells} / \mathrm{cm}^{2}$ in 24-well plates (Asahi Technoglass Co., Chiba, Japan).

1. Reverse transcriptase polymerase chain reaction (RT-PCR)

Expression of the mDNA of DSPP, which codes dentin DSP and DPP, in the culture cells was investigated by RT-PCR. First-strand cDNA was synthesized with a SuperScript III Cells Direct cDNA Synthesis System (Invitrogen Life Technologies, Carlsbad, CA, USA) in both the experimental group and control group. First-strand cDNA $(2 \mu \mathrm{l})$ was diluted in a $50 \mu \mathrm{l}$ PCR reaction mixture (10× PCR Ex Taq Buffer, $1.5 \mathrm{ml} \mathrm{MgCl}_{2}, 0.2 \mathrm{mM}$ each of dNTP, 0.25 units of TaKaRa Ex Taq (TaKaRa BIO), 10 pmol of each specific primer set: DSPP (forward primer: 5'-CAC ATC CAG GAA CCG GAG CAC A-3', reverse primer: $5^{\prime}-\mathrm{CCT}$ TAC TCT CCT TTG CTT CTT C-3', product size: 330 bp; SIGMA-ALDRICH JAPAN, Tokyo, Japan), G3PDH (forward primer: 5'-ACC ACA GTC CAT GCC ATC AC-3', reverse primer: 5'-TCC ACC ACC CTG TTG CTG TA-3', product size: 450 bp; SIGMA-ALDRICH JAPAN). ${ }^{74}$ 14) The reactions were performed in a thermal cycler (TaKaRa PCR Thermal Cycler PERSONAL, TaKaRa $\mathrm{BIO})$ at $94^{\circ} \mathrm{C}$ for $2 \mathrm{~min}, 25$ cycles of $94^{\circ} \mathrm{C}$ for $45 \mathrm{sec}, 50^{\circ} \mathrm{C}$ for $30 \mathrm{sec}$, and $72^{\circ} \mathrm{C}$ for $45 \mathrm{sec}$, followed by $72^{\circ} \mathrm{C}$ for $7 \mathrm{~min}$. Amplified samples, $5 \mu \mathrm{l}$ each were analyzed by $1.5 \%$ agarose gel electrophoresis at $100 \mathrm{~V}$ for $30 \mathrm{~min}$, stained with a $0.2 \mu \mathrm{g} /$ $\mathrm{ml}$ ethidium bromide solution (Nacalai Tesque) for $30 \mathrm{~min}$, and examined under ultraviolet light (ATTO, Tokyo, Japan).

\section{Alkaline phosphatase activity}

Alkaline phosphatase (ALP) enzyme activity, which is closely associated with cell differentiation, was assessed in 3-, 7-, and 14-day cultured cells by using an Alkaline Phosphatase Substrate Kit (BioRad Lab., Hercules, CA, USA) according to the manufacturer's instructions, and the absorbance at $405 \mathrm{~nm}$ was estimated in a plate reader (Wallac ARVO 1420 Multilabel Counter, WALLAC OY,
Turku, Finland). To evaluate cell proliferation in each well based on the DNA content, the cells were ruptured in TRIS buffer solution, and after fluorescence-staining the cell fragments with Bisbenzimide H 33258 (Wako), fluorescence intensity (excitation wave length: $355 \mathrm{~nm}$, detection wave length: $460 \mathrm{~nm}$ ) was mesured in the plate reader. Alkaline phosphate activity was adjusted for the the amount of DNA.

\section{Formation of calcifying loci}

The 3-, 7-, and 14-day cultures in plates were examined for calcification loci by fixation in formalin $(10 \%)$ and staining with alizarin red $\mathrm{S}(1 \%$; SIGMA-ALDRICH JAPAN).

\section{Transplantation}

After the 3rd passage, dental-pulp-derived cells $\left(1.5 \times 10^{7}\right.$ cells $)$ were isolated with trypsin-EDTA (0.05\% Trypsin, $0.53 \mathrm{mM}$ EDTA - 4Na; Gibco) and aggregated by mixing them with alginate solution $(1.5 \%, 0.3 \mathrm{ml}$; Protanal FL 10/60 Sodium Alginate; FMC Bio Polymer, Drammen, Norway) and $\mathrm{CaSO}_{4}$ $(21 \%, 40 \mu \mathrm{l})$. The cell clusters were subcutaneously but supra-fascially transplanted into the dorsolumbar area of KSN/Slc-nu/nu nude mice (7-weeksold, male, Japan SLC, Inc, Hamamatsu, Japan). Implantation of alginate alone was performed in the control group. After 6 weeks, soft X-ray (Softex) radiographs $(25 \mathrm{kVp}, 20 \mathrm{~mA}, 10 \mathrm{sec}$; Industrial X-Ray Film FR, Fuji Photo Film Co., Ltd.) of the mice were taken with a SOFTEX CSMW-2 (Softex Co., Kanagawa, Japan). The mice were then fixed by intra-cardiac perfusion with paraformaldehyde (4\%), and the tissue containing the implanted cell cluster or alginate alone was dissected out, immersed in the fixative for 2 hours, and rinsed in Naphosphate buffer solution several times. It was then demineralized with EDTA (4.3\%) for 2 weeks, rinsed again with the buffer, and embedded either in paraffin or TAAB 812 resin (TAAB Lab. Equip. Ltd., Berkshire, UK) and then processed for light microscopy and transmission electron microscopy, respectively. Some unfixed samples from both the experimental group and control group were freezeembedded in carboxymethyl cellulose sodium salt in distilled water and sectioned for histological studies.

The materials and methods used for histological examination are summarized in a flowchart (Flowchart).

\section{Light microscopy}

The paraffin-embedded tissue containing the implant was cut into $2 \mu \mathrm{m}$ sections with an HM400R microtome (MICROM GmbH, Walldorf, Germany) 


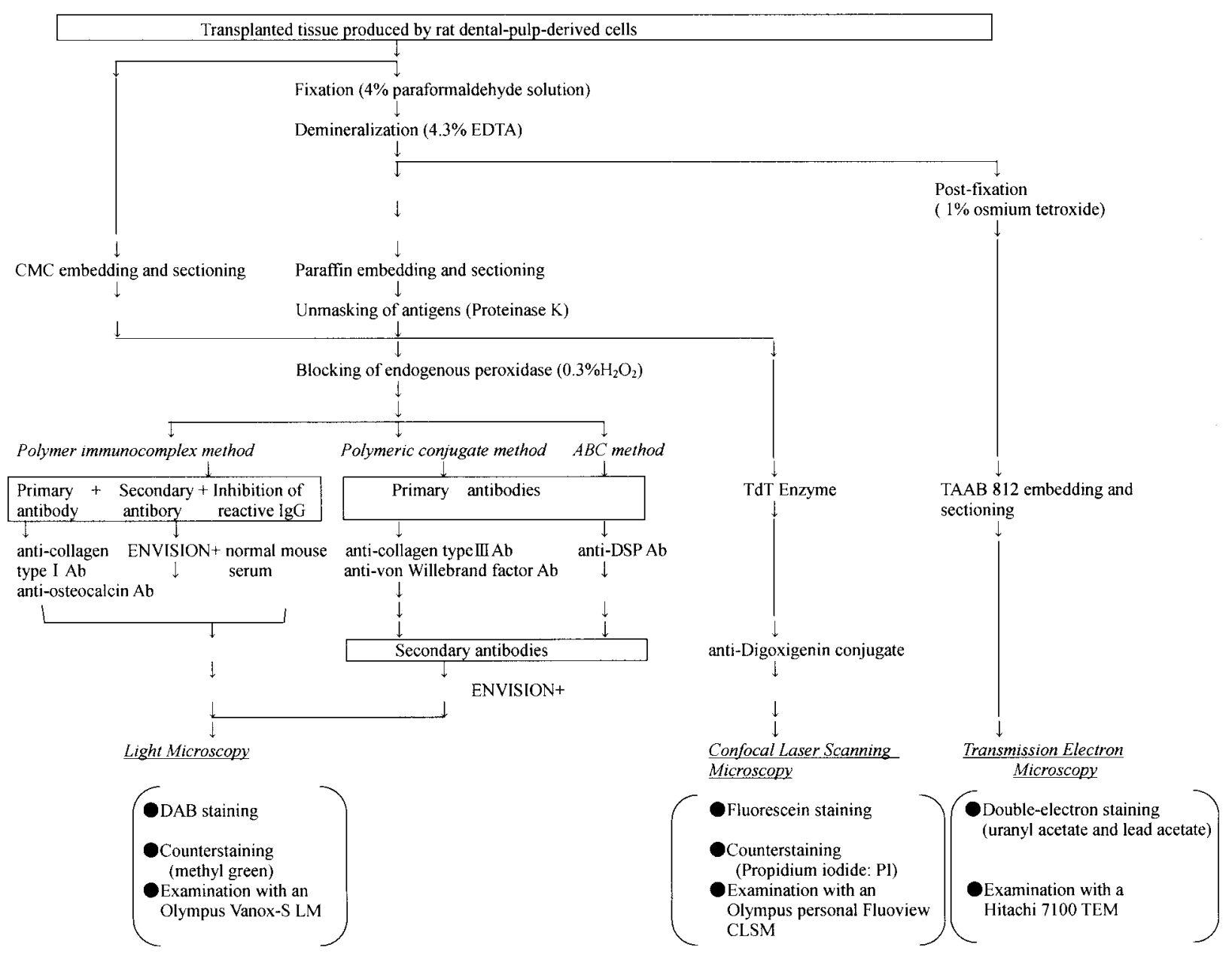

Flowchart: Assay procedures for light microscopy, confocal laser scanning microscopy, and transmission election microscopy

and routinely stained with $\mathrm{H}-\mathrm{E}$. The specimens were examined and photographed under an Olympus BX 41 light microscope (Olympus, Tokyo, Japan).

The polymer immunocomplex method was used for immunological study of secretion of type I collagen in the transplants. Mouse monoclonal collagen type I antibody (COL-1; $150 \times$ dilution; Abcam Ltd., Cambridgeshire, UK) and monoclonal antibody to bovine osteocalcin (Clone No. OC4-30, TaKaRa Bio) were used as the primary antibodies. Envision/HRP (DakoCytomation, Inc., Carpintera, CA, USA) was used as the secondary antibody, and normal mouse serum (DakoCytomation, Inc.) was used to block excessive reactions. The specimens were counterstained with methyl green for light microscopy.

The polymeric conjugate method was applied to observe type III collagen and angiogenesis in the transplants immunologically by using Type III Collagen (1000× dilution; LSL Co., Ltd. Tokyo, Japan) and polyclonal rabbit anti-Human Von Willebrand Factor (factor VIII; 1000× dilution; DakoCytomation, Inc.), respectively as the primary antibodies. The specimens were then immunoreacted with secondary antibody using the Envision/HRP (DAB) kit (DakoCytomation, Inc.) and counterstained with methyl green for light microscopy.

To detect of DSP in the specimens by the ABC method, goat polyclonal DSP (M-20) $(100 \times$ dilution; Santa Cruz Biotech Inc., Santa Cruz, CA, USA) and an Elite Vectastain ABC KIT (Vector Lab Inc., Ca, USA) were used as the primary antibody and secondary antibody, respectively, and the specimens were then stained with $\mathrm{DAB}$, and counterstained with methyl green for light microscopy. Freeze-embedded samples from the control group were sectioned $5 \mu \mathrm{m}$ thick with a CM3050S cryostat (Leica Microsystems Nussloch GmbH, Nussloch, Germany), then H-E stained and examined and photographed with an Olympus BX 41 light microscope (Olympus, Tokyo, Japan). 


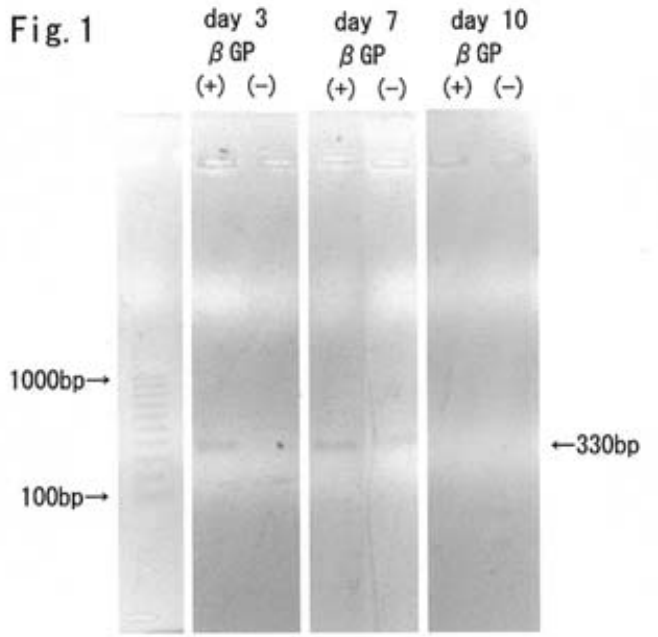

Fig. 2

ALP activily
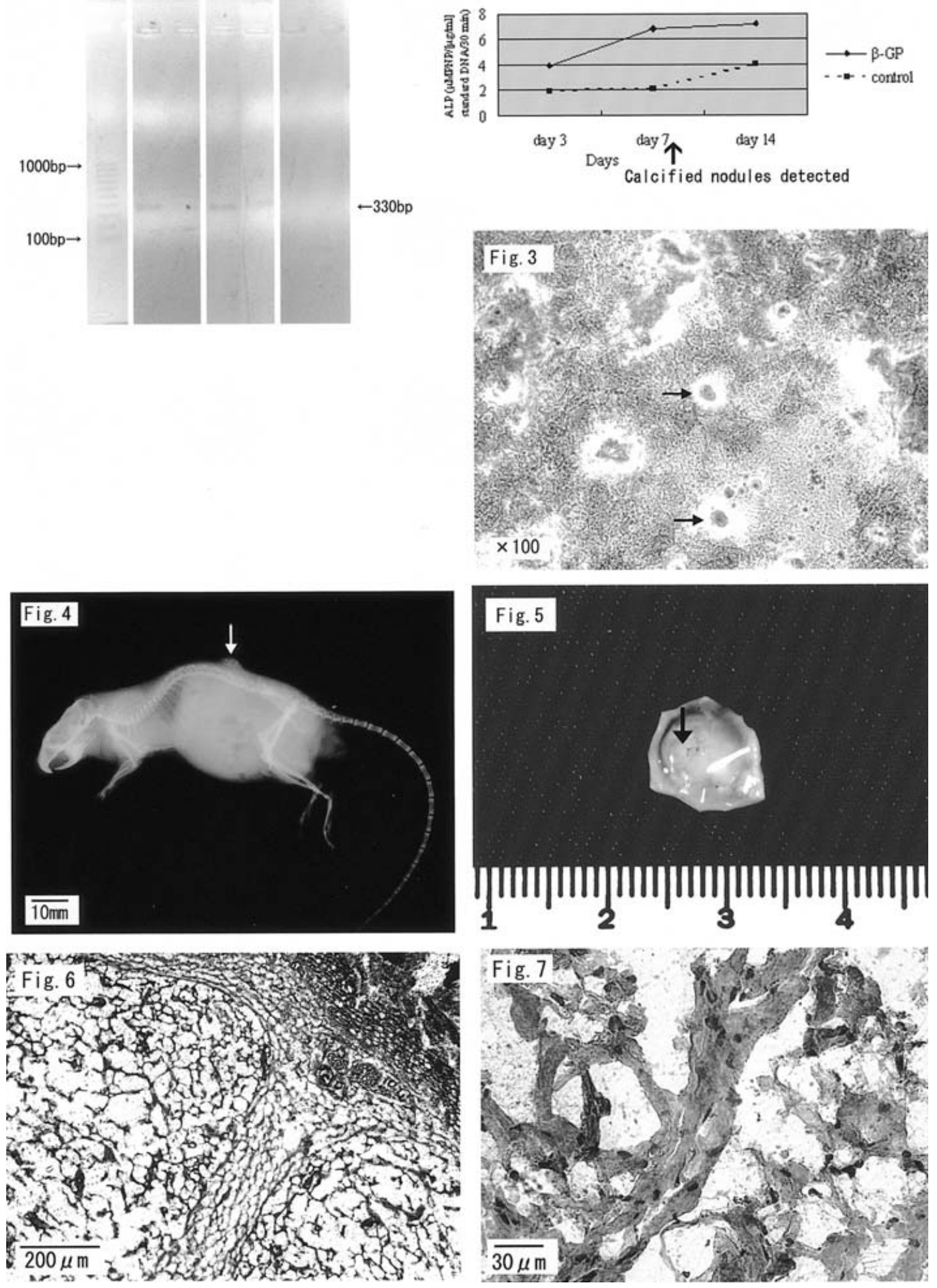
2. Confocal laser scanning microscopy

The TUNEL method was applied to paraffin sections with an ApopTag Plus Fluorescein In Situ Apoptosis Detection Kit (CHEMICON Intl., Inc., Temecula, CA, USA) to investigate cell turnover in the transplants. The DNA fragments were immunoreacted with TdT enzyme (CHEMICON Intl., Inc.) and anti-digoxigenin conjugate (CHEMICON Intl., Inc.), and the nuclei were counterstained for $30 \mathrm{~min}$ at room temperature with propidium iodide (PI; fluorescence wavelength: $615 \mathrm{~nm}$; Molecular Probes, Eugene, OR, USA). The specimens were examined and images recorded with an Olympus personal FLUOVIEW confocal laser scanning microscope (CLSM; FLUOVIEW Ver 2.00; argon ion laser, excitation wave length: $488 \mathrm{~nm}(\mathrm{CH} 1)$; HeNe ion laser, excitation wave length: $543 \mathrm{~nm}(\mathrm{CH} 2)$; filters: BA $510 \mathrm{~F}$, BA 530 (CH 1), BA 590, BA 565 (CH 2); Olympus).

\section{Transmission electron microscopy}

The TAAB 812-embedded samples were cut ultrathin with a diamond knife mounted on an LKB 4800 A ULTOTOME I (LKB, Stockholm, Sweden), picked up on 150-mesh copper grids, stained with uranyl acetate $(20 \mathrm{~min})$ and lead citrate (10 min), and then examined and photographed with a Hitachi HU-7100 transmission electron microscope (TEM) (Hitachi, Tokyo, Japan).

\section{Results}

\section{Cell differentiation}

1. RT-PCR

There was no expression of DSPP mRNA in the $\beta$-GP (-) primary and secondary passage cells. However, when $\beta$-GP was added to the medium, expression of DSPP mRNA was detected in the 3rd passage cells on day 3 of culture (Fig. 1).

\section{ALP activity}

ALP activity in the $\beta$-GP $(+)$ group was twice as high as in the $\beta$-GP $(-)$ group on the 3rd day of culture, and it clearly continued to increase until 7 days. No significant difference in ALP activity was observed in the $\beta$-GP (-) group between day 3 and day 7 of culture, but ALP activity in the $\beta$-GP (-) group had increased by day 14 of culture. However, on day 14 of culture, ALP activity in the $\beta$-GP (+) group was more than twice as high as in the $\beta$-GP (-) group (Fig. 2).

\section{Calcification loci}

Occurrence and concrescence of calcification loci were first observed on day 8 of culture, and the loci were composed of isolated proliferating and differentiating 3rd passage dental pulp cells (Fig. 3).

\section{Transplantation}

Softex radiography revealed radiopaque calcified bodies in the subcutaneously transplanted cell/ alginate clusters (Fig. 4). We dissected the transplants with the surrounding tissue and observed some whitish hard granules in the transplants (Fig. 5).

\section{Light microscopy}

1-1 Control group (implantation of alginate scaffold alone)

1) H-E staining: A network of strands of invading mesenchyme was observed in the transplants (Figs. 6 and 7).

2) Mouse monoclonal collagen type I antibody: Type I collagen immunoreactivity was evident in the network in the transplants (Fig. 8).

1-2 Experimental group (transplantation of cell clusters containing subcultured cells plus the alginate scaffold)

1) H-E staining: Formation of extracellular

Fig. 1. Electrophoresis of DSPP cDNA. When $\beta$-GP was added to the culture medium, expression of DSSP mRNA was observed from the 3rd day of culture onward.

Fig. 2. ALP activity of the cultured cells. On days 3, 7, and 14 of culture, ALP activity in the $\beta$-GP (+) group was twice as high or higher than in the $\beta$-GP $(-)$ group. Calcified nodules were found in the day 14 samples.

Fig. 3. Calcification of the cultured cells (Alizarin Red S staining). Occurrence and concrescence of calcification loci (arrows) were observed from day 8 of culture onward.

Fig. 4. Softex radiogram of a specimen 6 weeks after transplantation. Radiopaque calcified nodules were identified in a subcutaneously transplanted cell/alginate cluster (arrow).

Fig. 5. Photograph showing a dissected transplant containing cells clusters. Whitish hard granules are seen in the structure (arrow).

Fig. 6. Photomicrograph showing a transplant in the control group (implantation of alginate without cultured cells). The network of strands of cells is connected to surrounding mesenchymal cells.

Fig. 7. Photomicrograph showing an implant in the control group. Higher magnification of the cell strands in the implant. 

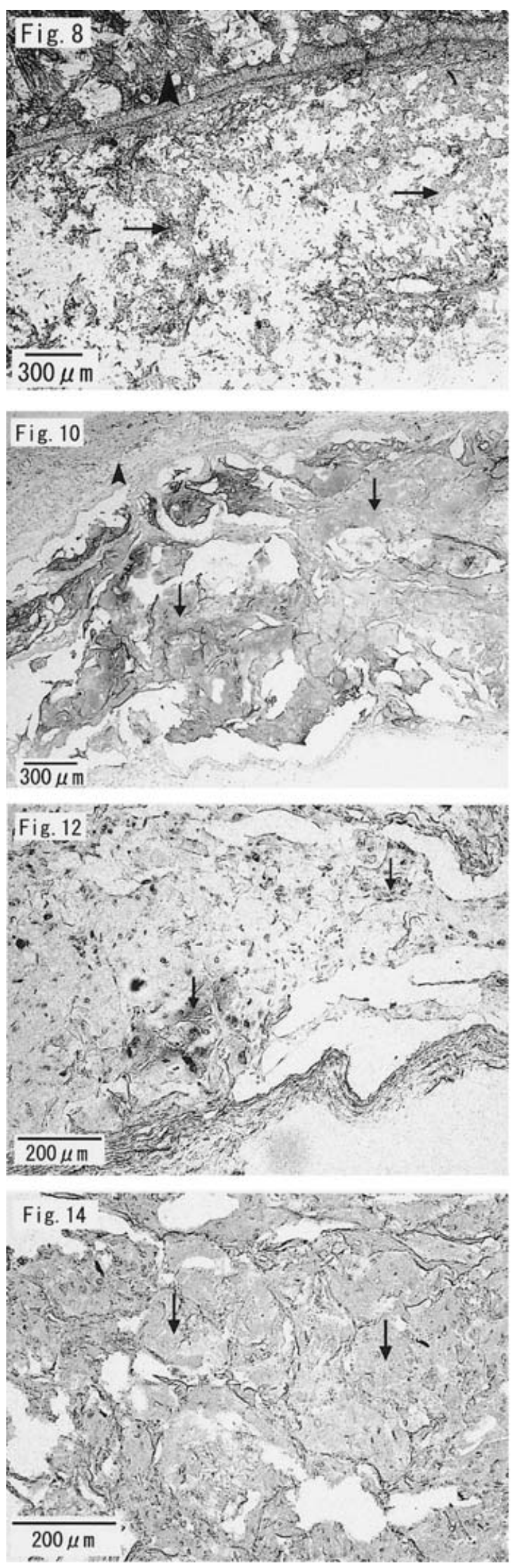
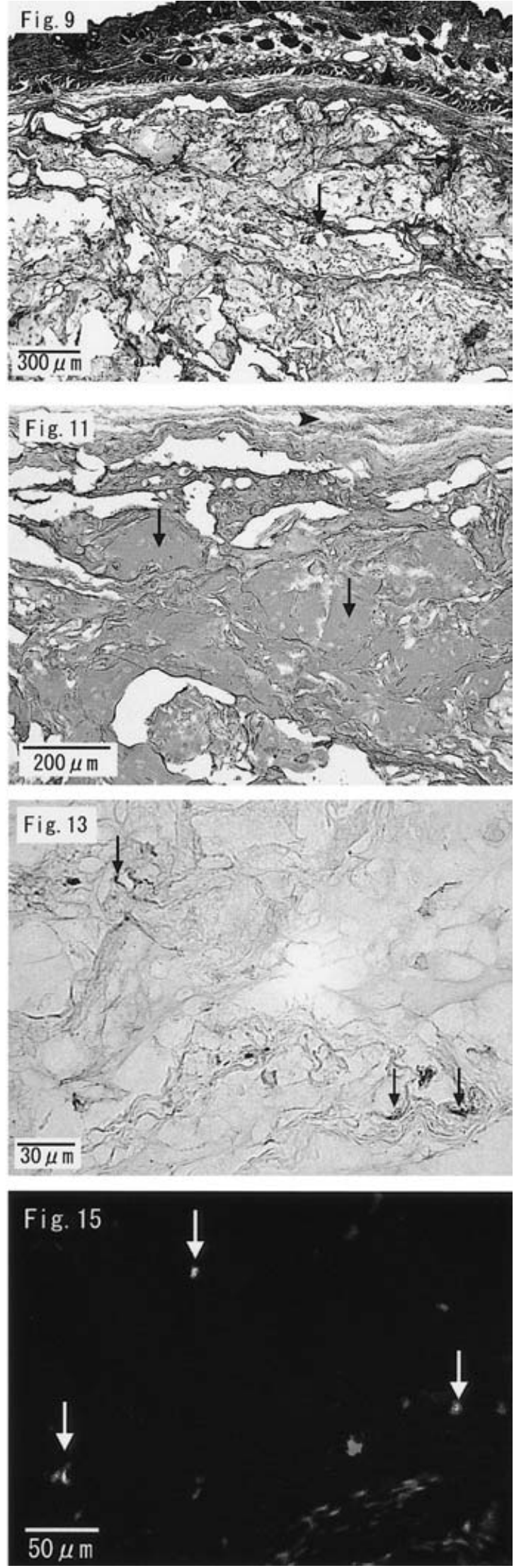
matrix (ECM) was observed in situ in the subcutaneous transplant containing 3rd passage cells, invading mesenchyme from the skin, and an alginate scaffold (Fig. 9).

2) Mouse monoclonal collagen type I antibody: Type I collagen was observed in the transplants (Fig. 10).

3) Rabbit Anti (bovine) Type III Collagen: Type III collagen was also noted in the transplants (Fig. 11).

4) Monoclonal Antibody to Bovine Osteocalcin: Osteocalcin was localized in the transplants (Fig. 12).

5) von Willebrand factor (factor VIII): Immunoreactivity was observed in the skin and in the network in the transplants (Fig. 13).

6) Goat polyclonal DSP (M-20): Expression of DSP, a characteristic non-collagenous protein usually observed in dentin, was evident in the transplants (Fig. 14).

2. Confocal laser scanning microscopy

Cell turnover: TUNEL $(+)$ cells were demonstrated in the calcifying transplants in the experimental group containing subcultured rat dentalpulp-derived cells (Fig. 15).

\section{Transmission electron microscopy}

Fine structure study of the ultrathin-sectioned demineralized specimens revealed isolated spindleshaped and elongated fibroblast-like cells in the transplants, and the intercellular junctional apparatuses of the isolated cells were not well developed (Fig. 16). Bundles of collagen fibrils were demonstrated in the demineralized ECM (Figs. 17, 18). Scattered autolyzing cells containing a disintegrat- ing nucleus and many lysosomes were found in the transplants (Fig. 19).

\section{Discussion}

Previous studies have reported differentiation of odontoblast-like cells and matrix calcification in cultures of dental-pulp-derived cells from rat, human, and cattle teeth ${ }^{15-18)}$. The well-developed odontoblast-like cells were characterized by cell polarization and distal extension of the main cell process. The differentiated cells also expressed DSPP related to the specific DSP and DPP found in dentin ${ }^{15}$. On the other hand, many studies have been conducted on factors that induce mesenchymal stem cells to differentiate into various tissues, and the results showed that bone formation was induced by dexamethasone, $\beta$-GP, Vitamin D, ascorbic acid, and BMP, while cartilage formation was induced by dexamethasone, ascorbic acid, TGF- $\beta$, and $\mathrm{BMP}^{1)}$. Another study, however, reported that $\beta$-GP was essential to induce cultured dental pulp-derived cells to acquire odontoblast properties ${ }^{15)}$.

A study on changes in ALP activity in cultured dental pulp cells found that their ALP activity peaked at the turning point between the proliferation phase and the differentiation phase. That study indicated that ALP activity can be used as a marker for the initial differentiation of odontoblasts ${ }^{7)}$. The same study on human dental pulp cells showed that ALP activity significantly peaked on day 9 in a $\beta$-GP ( + ) culture, and reported the presence of calcified nodules ${ }^{19}$. The increase in expression of the DSPP gene coincided with initial dentinogenesis, and thus provided a marker of odontoblast

Fig. 8. Immunohistochemistry of type I collagen (arrowhead points to the epidermis) in the control group. Type I collagen (+) immunoreactions are observed in the implant (arrows).

Fig. 9. Photomicrograph showing a transplant (experimental group containing alginate and subcultured cells) and surrounding tissue (H-E staining; arrowhead points to the epidermis). Invasion of the transplant by surrounding cells is observed (arrows).

Fig. 10. Immunohistochemistry of type I collagen (arrowhead points to the epidermis) in the experimental group. Type I collagen $(+)$ immunoreactions are observed in the transplant (arrows).

Fig. 11. Immunohistochemistry of type III collagen (arrowhead points to the epidermis) in the experimental group. Type III collagen $(+)$ reactions are present in the transplant (arrows).

Fig. 12. Immunohistochemistry of osteocalcin (arrows) in the experimental group. Osteoclacin $(+)$ reaction is demonstrated in the transplant containing subcultured rat dental-pulp-derived cells and the alginate scaffold.

Fig. 13. Immunohistochemistry of von Willebrand factor (factor VIII) in the experimental group. Expression of von Willebrand factor is evident in the network that formed in the transplant (arrows). The network is connected to the vascular system of the skin.

Fig. 14. DSP $(+)$ Immunoreactivity in the experimental group implant (an arrowhead points to the cell nucleus). A DSP (+) reaction suggests dentin-like tissue formation (arrows).

Fig. 15. Confocal laser scanning microscopic appearance of the transplant (experimental group) in situ TUNEL (+) cells (arrows) are demonstrated in the calcified transplant. 

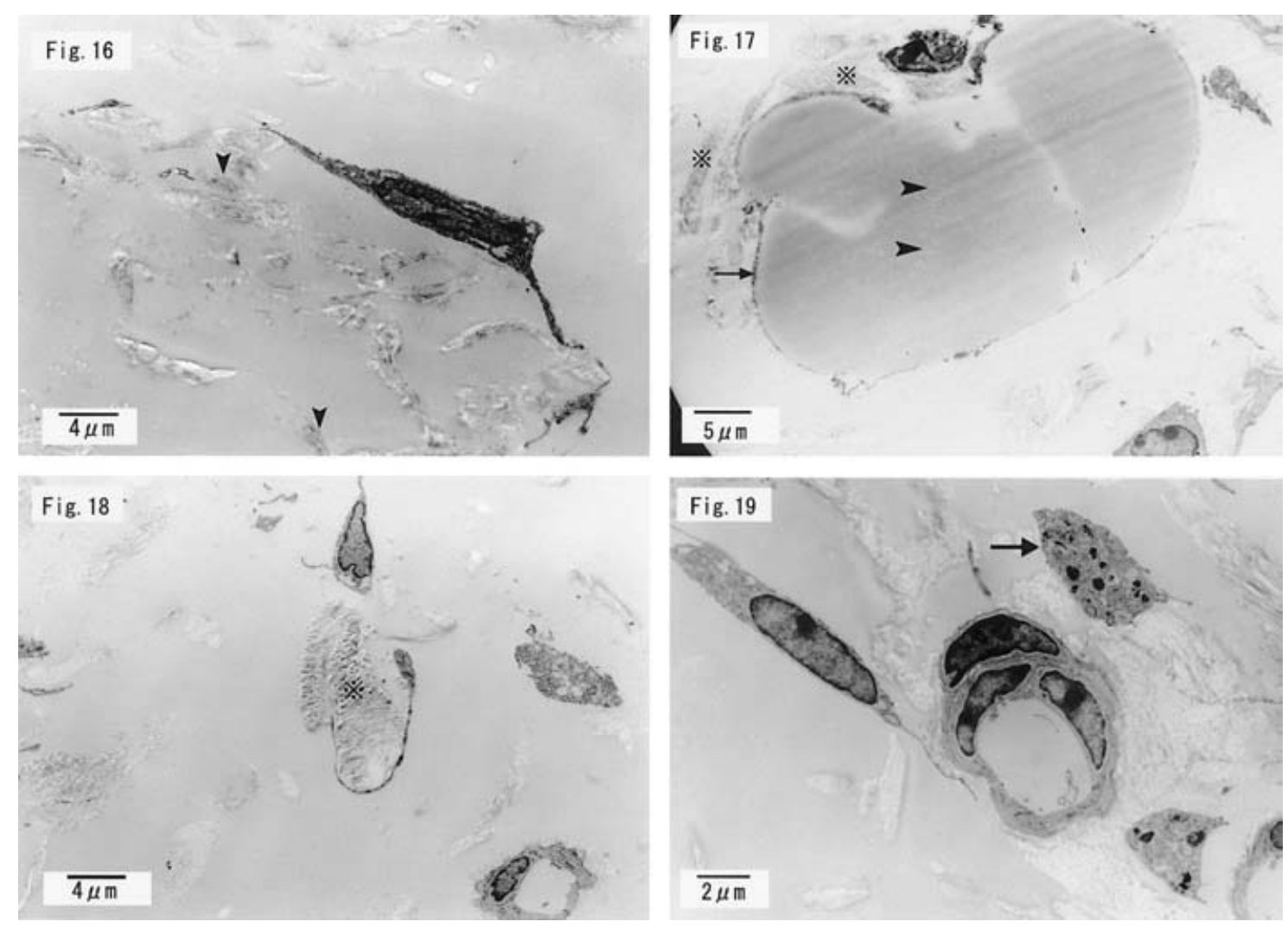

Fig. 16. Transmission electron microscopic appearance of a transplant in the experimental group. Isolated and polarized cells with long cell processes contain abundant cytoplasm; the intercellular junctional apparatuses are not well developed. Bundles of collagen fibrils are evident in the ECM (arrowheads).

Fig. 17. Transmission electron microscopic appearance of a transplant in the experimental group. The fibroblast-like cells have long thin cell processes (arrow) extending to surround the residual alginate material (arrowheads). Bundles of collagen fibrils are also seen in the calcified ECM (※).

Fig. 18. Transmission electron microscopic features of a transplant in the experimental group. The fibroblast-like cells have surrounded the ECM with bundles of collagen fibrils ( $※)$.

Fig. 19. Transmission electron microscopic appearance of a transplant in the experimental group. A capillary network is observed in $\mathrm{ECM}$ of the calcifying transplant. An apoptotic cell indicating turnover of the transplanted cells is demonstrated (arrow). Some cytoplasm-rich cells and abundant collagen fibrils are observed in the ECM.

maturation $^{15,20)}$. Also, formation of calcifying nodules by human dental pulp cultures has been found to occur between day 10 and 15 of culture ${ }^{21)}$.

In the present study we cultured 3 passages of rat dental pulp cells. No DSPP mRNA was found except in succeeding $\beta$-GP $(+)$ cultures. ALP activity in both the $\beta$-GP $(+)$ group and $\beta$-GP $(-)$ group was observed on the 3rd day of culture, but the ALP activity in the $\beta$-GP $(+)$ group was twice as high as in the $\beta$-GP $(-)$ group. ALP activity had doubled by the 7 th day of culture in the $\beta-G P(+)$ group, and it continued to increase slightly until the 14 th day of culture. No significant difference in ALP activity were observed in the $\beta$-GP (-) group between day 3 and day 7 of culture, but ALP activity in the $\beta$-GP (-) group had increased by the 14th day of culture. The expression of ALP activity and DSPP induced by $\beta$-GP indicated that odontoblast-like cells had differentiated in the 3rd passage cells. We also observed that ALP activity became marked during the 14th day of culture, but, calcifying loci were also observed on day 14 . These findings were consistent with the results of a previous study that correlated temporo-spatial changes in ALP activity and calcosphericle formation by human dental-pulp-derived fibroblasts ${ }^{19,21)}$.

Odontoblast-like cells have been found in transplants of human dental pulp cells with a HA/TCP scaffold in nude mice ${ }^{10)}$. The alginate scaffold, on the other hand, has been found to be particularly 
useful for 3-D culture of cartilage ${ }^{13,22-25)}$. In the present study we transplanted cultured rat dental pulp cells with an alginate scaffold and observed formation of radiopaque calcifying bodies in situ 6 weeks after transplantation. Immunohistochemical light microscopy revealed type I and type III collagen, while transmission electron microscopy demonstrated D periodicity of the matrix fibrils in the calcified transplants. These findings indicated that secretion of type I collagen and mineral deposition by the rat dental pulp-derived cells in the alginate scaffold are essential for calcification of the transplants.

DSP and DPP are proteins specific to dentin and are odontoblast differentiation markers ${ }^{26,27)}$. Dentin non-collagenous protein comprises $50 \%$ of DSP and DPP, which are coded by the DSPP gene ${ }^{28,29)}$. In the present study we identified the mRNA of the DSPP gene in cell cultures and demonstrated the presence of DSP in the subcutaneous calcifying transplant in situ. The differentiation of elongated fibroblast-like cells with extension of cell processes and deposition of calcifying loci observed by transmission electron microscopy suggests the formation of dentin-like tissue in the transplants.

In the present study we observed invasion of the transplants by capillaries from the skin, and the development of endothelial cells coincided with the distribution of factor VIII in the transplants. We identified calcified tissue in the transplants with the monoclonal antibody to bovine osteocalcin, which detects matricial osteocalcin of rat, human, and bovine origin but not of mouse origin. This findings demonstrated calcified tissue formation by the transplanted rat dental-pulp cells, but not by mouse mesenchymal cells carried by the invading blood vessels.

We also observed hard tissue formation, except in transplants of cell clusters containing subcultured cells, but no calcified bodies were demonstrated in the alginate-transplanted control group. These results indicated that the calcification was initiated by the rat dental-pulp-derived cells in the transplants.

In a previous study depression of cell vitality and apoptosis were observed among the chondrocytes in the middle layer of a culture on an alginate scaffold $^{13)}$. On the other hand, apoptosis has been found to be a phenomenon that occurs during the differentiation of odontoblasts ${ }^{30,31)}$. Confocal laser scanning microscopy in our study identified TUNEL (+) reactions in cell strands distributed in the alginate scaffold, and their histological appearance suggested depression of vitality and turnover of the differentiating odontoblast-like cells.

The present study revealed differentiation of odontoblast-like cells and dentin-like tissue forma- tion in the transplants, which led us to conclude that alginate scaffolds support the differentiation of cultured cells in transplants. However, since the transplants initiated dentin-like tissue formation in a specific environment that differed from the usual environment in which dentinogenesis occurs, a study to clarify the mechanism of maturation and aging of the transplants should be the next study in programming remodeling of the regenerated hard tissue.

\section{Acknowledgements}

We would like to express our gratitude to Michiko Nakatsuka, DDS, and Fumiko Aikawa, DDS, of the Department of Oral Anatomy, for their valuable assistance in this research and helpful suggestions.

The Laboratory Animal Facilities, Morphological Research Facilities, Tissue Culture Facilities, and Dental Bioscience Facilities I of the Institute of Dental Research, Osaka Dental University, were used to perform this study. The study was supported by a grant-in-aid from the Osaka Dental University Joint Research Funds (B03-01).

\section{References}

1) Tuan RS, Boland G and Tuli R. Adult mesenchymal stem cells and cell-based tissue engineering. Arthritis Res Ther 2003; 5:32-45.

2) Pittenger MF, Mackay AM, Beck SC, Jaiswal RK, Douglas R, Mosca JD, Moorman MA, Simonetti DW, Craig S and Marshak DR. Multilineage potential of adult human mesenchymal stem cells. Science 1999; 284:143-147.

3) Awad HA, Butler DL, Harris MT, Ibrahim RE, Wu Y, Young RG, Kadiyala $S$ and Boivin GP. In vitro characterization of mesenchymal stem cell-seeded collagen scaffolds for tendon repair: Effects of initial seeding density on contraction kinetics. J Biomed Mater Res 2000; 51:233-240.

4) Wakitani S, Saito T and Caplan AI. Myogenic cells derived from rat bone marrow mesenchymal stem cells exposed to 5-azacytidine. Muscle Nerve 1995; 18:1417-1426.

5) Majumdar MK, Thiede MA, Haynesworth SE, Bruder SP and Gerson SL. Human marrow-derived mesenchymal stem cells (MSCs) express hematopoietic cytokines and support long-term hematopoiesis when differentiated toward stromal and osteogenic lineages. J Hematother Stem Cell Res 2000; 9:841-848.

6) Takeyasu M, Nozaki T, Watanabe M, Shinohara M, Morita J, Hidaka A, Iwamoto K, Takahashi T, Nagata S, Daito M and Ohura K. In vitro osteogenic differentiation potential of dental pulp stem cells. J Oral Tissue Engin 2004; 2:25-30.

7) Yokose S, Kadokura H, Tajima Y, Fujieda K, Katayama I, Matsuoka T and Katayama T. Establishment and characterization of a culture system for enzymatically released rat dental pulp cells. Calcif Tissue Int 2000; 66:139-144.

8) Sachlos E and Czernuszka JT. Making tissue engineering 
scaffolds work. Review on the application of solid freeform fabrication technology to the production of tissue engineering scaffolds. Eur Cell and Mater 2003; 5:29-40.

9) Tsang VL and Bhatia SN. Three-dimensional tissue fabrication. Adv Drug Deliv Rev 2004; 56:1635-1647.

10) Gronthos S, Mankani M, Brahim J, Robey PG and Shi S. Postnatal human dental pulp stem cells (DPSCs) in vitro and in vivo. PNAS 2000; 97:13625-13630.

11) Becker TA, Kipke DR and Brandon T. Calcium alginate gel: A biocompatible and mechanically stable polymer for endovascular embolization. J Biomed Mater Res 2001; 54:76-86.

12) Domm C, Schunke M, Steinhagen J, Freitag S and Kurz B. Influence of various alginate brands on the redifferentiation of dedifferentiated bovine articular chondrocytes in alginate bead culture under high and low oxygen tension. Tissue Eng 2004; 10:1796-1805.

13) Heywood HK, Sembi PK, Lee DA and Bader DL. Cellular utilization determines viability and matrix distribution profiles in chondrocyte-seeded alginate constructs. Tissue Eng 2004; 10:1467-1479.

14) Dey R, Son HH and Cho MI. Isolation and partial sequencing of potentially odontoblast-specific/enriched rat cDNA clones obtained by suppression subtractive hybridization. Arch Oral Biol 2001; 46:249-260.

15) Couble ML, Farges JC, Bleicher F, Perrat-Mabillon B, Boudeulle $\mathrm{M}$ and Magloire $\mathrm{H}$. Odontoblast differentiation of human dental pulp cells in explant cultures. Calcif Tissue Int 2000; 66:129-138.

16) Kasugai S, Shibata $S$, Suzuki S, Susami $T$ and Ogura $H$. Characterization of a system of mineralized-tissue formation by rat dental pulp cells in culture. Arch Oral Biol 1993; 38:769-777.

17) Seux D, Couble ML, Hartmann DJ, Gauthier JP and Magloire H. Odontoblast-like cytodifferentiation of human dental pulp cells in vitro in the presence of a calcium hydroxide-containing cement. Arch Oral Biol 1991; 36:117-128.

18) Nakashima M. Establishment of primary cultures of pulp cells from bovine permanent incisors. Arch Oral Biol 1991; 36:655-663.

19) Sakamoto M, Okabe T, Matsushima K, Kawashima T,
Takeuchi $\mathrm{H}$ and Yamazaki M. Effect of $\beta$-glycerophosphate on mineralization of human dental pulp cells. Nihon Univ $\mathbf{J}$ Oral Sci 2004; 30:113-119. (in japanese)

20) Bleicher F, Couble ML, Farges JC, Couble P and Magloire H. Sequential expression of matrix protein genes in developing rat teeth. Matrix Biol 1999; 18:133-143.

21) Tsukamoto $Y$, Fukutani S, Shin-Ike T, Kubota T, Sato S, Suzuki Y and Mori M. Mineralized nodule formation by cultures of human dental pulp-derived fibroblasts. Archs Oral Biol 1992; 37:1045-1055.

22) Dar A, Shachar M, Leor J and Cohen S. Optimization of cardiac cell seeding and distribution in 3D porous alginate scaffolds. Biotechnol Bioeng 2002; 80:305-312.

23) Dvir-Ginzberg M, Gamlieli-Bonshtein I, Agbaria R and Cohen S. Liver tissue engineering within alginate scaffolds: Effects of cell-seeding density on hepatocyte viability, morphology, and function. Tissue Eng 2003; 9:757-766.

24) Kataoka K, Suzuki Y, Kitada M, Hashimoto T, Chou H, Bai H, Ohta M, Wu S, Suzuki K and Ide C. Alginate enhances elongation of early regenerating axons in spinal cord of young rats. Tissue Eng 2004; 10:493-504.

25) Li Z, Ramay HR, Hauch KD, Xiao D and Zhang M. Chitosan-alginate hybrid scaffolds for bone tissue engineering. Biomaterials 2005; 26:3919-3928.

26) Ruch JV, Lesot H and Begue-Kirn C. Odontoblast differentiation. Int J Dev Biol 1995; 39:51-68.

27) Butler WT and Ritchie H. The nature and functional significance of dentin extracellular matrix proteins. Int J Dev Biol 1995; 39:169-179.

28) MacDougall M, Simmons D, Luan X, Nydegger J, Feng J and Gu TT. Dentin phosphoprotein and dentin sialoprotein are cleavage products expressed from a single transcript coded by a gene on human chromosome 4 . Dentin phosphoprotein DNA sequence determination. J Biol Chem 1997; 272:835-842.

29) Patel PI. Soundbites. Nat Genet 2001; 27:129-130.

30) Vaahtokari A, Aberg T and Thesleff I. Apoptosis in the developing tooth: association with an embryonic signaling center and suppression by EGF and FGF-4. Development 1996; 122:121-129.

31) Matalova E, Tucker AS and Sharpe PT. Death in the life of a tooth. J Dent Res 2004; 83:11-16. 